\title{
Humanismo e tecnologia na perspectiva da competência informacional e midiática
}

\author{
Aida Varela Varela \\ Marilene Lobo Abreu Barbosa \\ Maria Giovanna Guedes Farias
}

Resumo: O artigo contextualiza os avanços tecnológicos no âmbito da informação e comunicação na sociedade contemporânea, com ênfase nos novos recursos tecnológicos dos massmedia e sua apropriação pelo sujeito social, destacando-se o cenário brasileiro. Diante do exposto, objetivou-se, neste trabalho, refletir sobre as contradições entre a organização complexa do conhecimento, considerando os vários formatos e estruturas, proporcionados pela massmedia e a falta de proficiência do indivíduo para compreender, apropriar-se e transformar o conhecimento. Apresentam-se alguns resultados de estudos desenvolvidos sobre o tema em questão, por membros do grupo de pesquisa Ciência da Informação: Cognição, Mediação e Construção do Conhecimento (COGNICIC), no período de 2010 a 2015. Os resultados de pesquisa evidenciaram que professores e alunos demonstraram não ter atingido o nível satisfatório de domínio de habilidades e competências digitais e informacionais necessárias ao seu manejo, gestão e uso reflexivo no ambiente escolar e na sociedade; e, ainda, que problemas gerenciais e a falta de estrutura da escola e dos laboratórios multimídias vêm dificultando o processo de incorporação de tecnologias na sala de aula e de capacitação de professores como multiplicadores. Tais resultados reiteram o argumento defendido pelo grupo COGNICIC de que o desenvolvimento de competências e habilidades em leitura é pré-requisito para o acesso e participação nas redes colaborativas de construção do conhecimento. Em tese, a superação deste quadro de defasagem ocorrerá, caso sejam concebidos e executados projetos pedagógicos, que potencializem a formação de sujeitos críticos, criativos e protagonistas de sua autonomia.

Palavras-chave: Competência informacional. Competência midiática. Massmedia. Leitura-Proficiência. Humanismo.

\section{INTRODUÇÃO}

A sociedade contemporânea modula-se numa estrutura social e tecnológica globalizadora, que alicerça a construção de novas formas de atividades produtivas, econômicas, educativas, culturais e de lazer. Neste sentido, a integração do sujeito à 
sociedade contemporânea, que se caracteriza pela construção, apropriação e uso intensivo do conhecimento, só se efetiva mediante o desenvolvimento de um conjunto de competências essenciais, que o leva a compreender fatos e fenômenos, a estabelecer relações interpessoais e a analisar e refletir sobre a realidade complexa que envolve a nova ordem mundial, nos dias de hoje, fincada na economia global e nas tecnologias de informação e da comunicação.

É patente também o papel fundamental que as tecnologias da informação e da comunicação, sobretudo as soluções de redes digitais, vêm assumindo na educação, no desenvolvimento da ciência e na formação dos sujeitos sociais. Reforça-se, aqui, o entendimento de que a leitura crítica se constitui num recurso estruturante, indispensável para se transitar no mundo das redes sociais e colaborativas na perspectiva de aquisição e disseminação do conhecimento.

Neste sentido, a expectativa é de que os recursos midiáticos venham a ser utilizados como estratégias educacionais, de modo a incentivar o pensamento criador, a comunicação e o desenvolvimento da identidade sociocultural dos indivíduos, fortalecendo a atitude de questionamento, de perplexidade, o julgamento crítico e a imaginação e inventividade diante do mundo. Contudo, para conseguir extrair, de modo significativo, o potencial formador e educativo dos recursos midiáticos, é preciso que o sujeito tenha os pré-requisitos que o capacitem a fazer uma seleção crítica das informações e uma leitura significativa e transformadora dos conhecimentos neles veiculados, caso contrário, tais recursos podem representar um entrave e, em determinados casos, até uma ameaça.

Observa-se, também, que a falta de domínio das habilidades de leitura e de acesso à informação, acrescida da carência de infraestrutura tecnológica, entre comunidades, distancia ainda mais os historicamente excluídos dos privilegiados.

Com base nesses pressupostos, entende-se que o desafio se constitui na formação do leitor proficiente e na aplicação dos recursos tecnológicos no enriquecimento das ações pedagógicas, de modo que estes meios, - leitura e massmedia - atuem como subsídios na formação do sujeito, fortalecendo sua capacidade de reflexão, criticidade e criatividade. 
Assim, considerando a educação como mediadora da prática social e responsável pela concepção e execução de um projeto pedagógico integrador do conhecimento e dos vários recursos didáticos, voltado ao desenvolvimento das potencialidades humanas, tomou-se como objetivo deste trabalho refletir sobre as contradições entre a organização complexa do conhecimento, considerando os vários formatos e estruturas proporcionados pela massmedia, e a falta de proficiência do sujeito social para apropriar-se dele e transformá-lo, reiterando-se o argumento de que o desenvolvimento de competências e habilidades em leitura é pré-requisito para o acesso e participação nas redes colaborativas de construção do conhecimento, na perspectiva do aprofundamento da 'competência informacional e midiática' e de leitura de mundo.

\section{DA LEITURA À CRÍTICA E À LEITURA DE MUNDO: UM CAMINHO A PERCORRER}

A apreensão da informação presume a habilidade das pessoas para decodificar e processar informações simbólicas e de proficiência no falar, ler e escrever. Alguém capaz de analisar e discutir informações racionalmente, com perspicácia e discernimento, sem aceitar, de forma automática, suas próprias opiniões e as opiniões alheias, é um indivíduo dotado de senso crítico, com atitude de permanente curiosidade intelectual e indagação diante do obscuro e do novo. O sujeito crítico é dotado de consciência pragmática, da habilidade de pensar logicamente, de estruturar pensamentos argumentativos convincentes, de modo a influenciar outras pessoas, bem como de avaliar a veracidade dos fatos, questionar valores e conceitos, elucidando a problemática em debate.

De acordo com Kleiman (1999), a compreensão do conhecimento envolve processos cognitivos múltiplos, isto é, o conjunto de processos, atividades, recursos e estratégias mentais próprias do ato de compreender. Isso não quer dizer que compreender informações seja apenas um ato cognitivo, pois é também um ato social. É evidente, portanto, que leitura é a estratégia para a construção do conhecimento e a inserção social do sujeito, na medida em que ler não é um ato mecânico e, sim, a capacidade de 
compreender o discurso político, econômico, social, cultural que integra a rede que compõe o contexto.

Com a internet surge uma nova concepção de leitura. Primeiramente, pensou-se que a rede diminuiria a necessidade de leitura. Isso, no entanto, não está ocorrendo, porque qualquer pesquisa séria exige muita leitura; mesmo na web necessita-se fazer uma seleção do que é ou não importante. Assim, acaba-se lendo muito mais, em menos tempo, do que se leria em uma biblioteca. A leitura na rede também é muito mais interessante para as novas gerações que já não querem e não dispõem de mais tempo para longos textos lineares.

Faz-se mister, portanto, aproveitar esse novo espaço de aprendizagem, pois a leitura de textos não lineares potencializa outras competências cognitivas no sujeito, já que exige conexão entre ideias e conceitos articulados em links, que interligam diferentes linguagens, páginas, gêneros textuais etc., além de promover o desenvolvimento da compreensão relacionada ao campo semântico e à produção de sínteses.

Essa garantia se dá através da habilidade de ler, compreender e produzir gêneros textuais diversos. E, conforme Alliende (1987), a leitura é um processo de aquisição da lectoescrita e, como tal, compreende duas operações fundamentais: a decodificação e a compreensão. No processo de decodificação o sujeito identifica um signo gráfico através de um nome (sinal gráfico) de um som. Já a compreensão é a captação do sentido ou conteúdo das mensagens escritas. Sua aprendizagem se dá através do domínio progressivo de textos escritos cada vez mais complexos. Ainda segundo o autor, não se pode falar em compreensão sem abordar a leitura. E, quando se fala em leitura, são três as ações que definem sua função essencial: a) transformar, b) compreender e c) julgar. Transformar, em leitura, dá-se quando o leitor converte a linguagem escrita em linguagem oral; compreender, efetiva-se quando o leitor consegue captar ou dar sentido ao conteúdo da mensagem; julgar é a capacidade que o leitor tem de analisar o valor da mensagem no contexto social.

Por outro lado, os ambientes virtuais exigem algumas competências a mais. Em primeiro lugar, é necessário que o leitor tenha conhecimento da tecnologia para a leitura em ambientes virtuais; depois, é importante saber que em computador os textos são lidos 
$28 \%$ mais devagar e com menor grau de compreensão do que quando estão impressos, principalmente para principiantes, que precisam se habituar a novos formatos de textos, aos hiperlinks, às cores, aos flashes, além de outros recursos computacionais que podem tirar o foco da atenção do leitor, como a existência de telas poluídas, a abertura de várias janelas ao mesmo tempo etc., conforme enumera Stemler (1997).

Segundo Quin (1999), a linguagem visual, no mundo das mídias, é decisiva no desenvolvimento das pessoas. A habilidade para interpretar imagens implica habilidades de identificar e de prever ferramentas úteis para permitir a decodificação da linguagem de informação, uma vez que a linguagem e os textos estão carregados de valores, ideologias e formas de pensar sobre o mundo. Portanto, se os educadores souberem quais os gêneros textuais que os alunos utilizam em seu cotidiano, em sua profissão e quais os gêneros utilizados pela área em que estão buscando formação, eles terão mais condições de trabalhar com textos e ações pedagógicas mais significativas.

O alcance da proficiência em leitura requer a concepção de um projeto educativo sistêmico e eficiente, a ser desenvolvido gradativamente, em longo prazo, com o objetivo de despertar no sujeito a tomada de consciência do que sabe, pensa e sente, ao tempo em que desenvolve linguagem de diferentes contextos, permeada pela interativadade, proporcionada pelas novas tecnologias, ao tempo em que constrói identidades. No entanto, os indicadores sobre o potencial de leitura dos brasileiros apontam caminhos árduos para que se chegue a um patamar de leitura crítica e de visão do mundo, haja vista os indicadores apontados por instituições credenciadas, que promovem a avaliação destes índices periodicamente. Como ler, compreender e usar significativamente a informação sem proficiência em leitura?

A leitura é instrumento de construção de conhecimento e inserção social, desde que o leitor esteja apto a explorar este seu potencial, por meio do desenvolvimento de competências prévias de leitura, compreensão de texto e domínio de contexto. 


\section{OS INDICADORES DO ANALFABETISMO E DO ALFABETISMO NO BRASIL}

Os índices de domínio de leitura apresentados nas pesquisas brasileiras têm sido preocupantes, principalmente quando se confrontam estes indicadores com a complexidade da ciência, no que tange à profundidade com que os temas são tratados e em relação aos seus métodos e à riqueza de suas fontes de informação. Por tudo isto, o acesso ao conhecimento exige proficiência em leitura e domínio das ferramentas e sistemas de busca, recuperação e descobrimento de informações. Para traçar um pequeno cenário que evidencie a situação e ajude a refletir sobre o contexto, apresentam-se estudos realizados por instituições tradicionalmente dedicadas ao tema.

\subsection{Indicador de Alfabetismo Funcional - INAF}

O INAF, criado e implementado pelo Instituto Paulo Montenegro e pela ONG Ação Educativa, é aplicado desde 2001, por amostragem, a 2000 pessoas, entre 15 e 64 anos, residentes em zonas urbanas e rurais de todas as regiões do Brasil. O termo Alfabetismo, na pesquisa, considera os dois domínios: letramento (processamento de informação verbal em diversos formatos; compreensão e expressão escrita) e numeramento, capacidade de compreender e operar com noções e representações matemáticas envolvidas em situações cotidianas.

Na edição de 2011, O Instituto Paulo Montenegro, com base nos dados do INAF, pondera que os avanços quantitativos no nível de escolaridade da população não têm correspondido a ganhos qualitativos no domínio das habilidades de leitura, escrita e matemática. Somente $62 \%$ das pessoas com ensino superior e $35 \%$ das pessoas com ensino médio completo são classificadas como plenamente alfabetizadas. Em ambos os casos essa proporção é inferior ao observado no início da década. O INAF também revela que um em cada quatro brasileiros que cursam ou cursaram até o ensino fundamental II ainda estão classificados no nível rudimentar, sem avanços durante todo o período. 
A edição de 2015, de acordo com a classificação utilizada pelo INAF, qual seja, analfabetismo, alfabetismo rudimentar, alfabetismo elementar, alfabetismo intermediário e proficiente apresenta os seguintes resultados:

- A quantidade de pessoas classificadas como alfabetizadas funcionalmente alcança $73 \%$ da população investigada, o que também revela a manutenção do resultado obtido em 2011 no INAF Brasil.

- A maior parte dos respondentes, $42 \%$, foi classificada no grupo elementar, no qual, realizam a leitura de uma ou mais unidades de informação em textos diversos de extensão média realizando pequenas inferências.

- Cerca de um quarto do total (23\%) estava na condição intermediário, revelando habilidades de leitura, escrita e resolução de problemas condizentes com a localização de múltiplas informações, a resolução de problemas matemáticos complexos e com capacidade de sintetizar ideias centrais de textos e captar efeitos de sentido.

- Apenas $8 \%$ dos respondentes estão no último grupo de alfabetismo, revelando domínio de habilidades que praticamente não mais impõem restrições para compreender e interpretar textos em situações usuais e resolvem problemas envolvendo múltiplas etapas, operações e informações.

\subsection{Instituto Brasileiro de Geografia e Estatística e Pesquisa Nacional por Amostras de Domicílios}

Quase metade da população brasileira $(49,25 \%)$ com 25 anos ou mais não tem o ensino fundamental completo, segundo dados do Censo 2010 divulgados pelo IBGE (Instituto Brasileiro de Geografia e Estatística). O percentual representa 54,5 milhões de brasileiros. O índice é mais alto em áreas rurais, onde 79,6\% dos brasileiros nessa faixa etária não terminaram o ensino fundamental. Entre a população urbana, a taxa é de 44,2\%.

Outros 16 milhões $(14,65 \%)$ de pessoas com 25 anos ou mais concluíram o fundamental, mas não chegaram ao fim do ensino médio. Nessa faixa etária, 35,8\% da população concluiu, ao menos, o ensino médio e 11,26\% têm nível superior completo. 
Apesar do alto índice de habitantes que não terminaram o ensino fundamental, o índice demonstra avanço na escolaridade da população se comparada aos números do censo demográfico de 2000, quando $64 \%$ dos brasileiros não tinham concluído o fundamental.

Um quarto da população entre 20 e 24 anos não concluiu o ensino fundamental, enquanto $22,57 \%$ dos brasileiros nessa faixa etária não concluíram o ensino médio - o que representa 3,9 milhões de habitantes.

Entre os jovens de 18 a 24 anos, 36,5\% haviam abandonado o estudo antes de completar o ensino médio em 2010. Desses, a maioria $(52,9 \%)$ deixou a escola antes de terminar o ensino fundamental, enquanto 21,2\% abandonou o estudo logo após ingressar no ensino médio.

De acordo com dados da Pesquisa Nacional por Amostras de Domicílios (PNAD), divulgados este ano pelo IBGE, o brasileiro com mais de 15 anos estudou em média durante 7,7 anos. O tempo médio de estudo não é suficiente para completar o ensino fundamental, que dura nove anos.

Se considerada a população acima dos 10 anos de idade, o tempo médio de estudo é de 7,3 anos. Os melhores resultados estão entre as pessoas entre 20 e 24 anos (9,8 anos de estudo) e aqueles entre 25 e 29 anos (9,7 anos). E os piores, entre a população com mais de 60 anos (4,4 anos) e de 10 a 14 anos (4,2 anos).

\subsection{Retratos da Leitura no Brasil}

Segundo a publicação Retratos da Leitura no Brasil promovida pelo Instituto PróLivro em 2015, o índice de penetração de leitores aumentou comparada a edição realizada em 2011, passando de 50\% para 56\%. Essa oscilação ocorreu em praticamente todas as regiões brasileiras, com exceção do Nordeste, que permaneceu estável: Norte, de 47\% subiu para 53\%; Nordeste permaneceu com 51\% nas pesquisas de 2011 e 2015; Centro Oeste, de 53\% aumentou para 57\%; Sudeste, de 50\% para 61\%; e Sul, de $43 \%$ aumentou para $50 \%$. 
O Instituto Pró-Livro considerou que leitor é aquele que leu um livro inteiro ou em partes, pelo menos nos últimos três meses; e o não leitor é aquele que declarou não ter lido nenhum livro nos últimos três meses, mesmo que tenha lido nos últimos 12 meses.

Em relação à edição de 2011, houve um crescimento significativo da proporção de pessoas que já ouviram falar em livros digitais, 11 pontos percentuais. Entre esses, cerca de um quarto já leu algum livro digital. Ainda em relação à edição anterior, houve uma mudança significativa do tipo de suporte utilizado para leitura do livro digital. Os resultados da pesquisa de 2015 apontam os celulares ou smartphones como os principais suportes utilizados para a leitura do livro digital.

Assim como nas edições anteriores, a pesquisa confirma as principais correlações com a leitura: escolaridade, classe social e ambiente familiar. Quanto mais escolarizado ou mais rico é o entrevistado, maior é a penetração da leitura e a média de livros lidos nos últimos três meses. Esta situação de nítida exclusão aumenta a responsabilidade de todo o sistema educativo-cultural brasileiro, que tem de envidar esforços para combater este estado de defasagem da educação, que tanto impede o desenvolvimento econômico do país e o progresso da sociedade brasileira. Diante deste cenário, uma questão se torna inevitável: o que fez e faz o Brasil para atacar este problema e encontrar sua solução?

No limiar do Século XXI, a Unesco realizou estudos e ações, com a perspectiva de fomentar a reflexão e trazer novas ideias e princípios que pudessem ajustar as teorias e práticas educacionais às exigências dos novos tempos, conturbados pela voracidade da economia, pelas disputas políticas, mas, principalmente, pelas transformações impostas pelas tecnologias de informação e de comunicação ao mundo dos negócios, do trabalho e à vida da sociedade em geral. Era premente rever e ajustar o sistema educativo. E muitos países, capitaneados pelos estudos da Unesco, promoveram reformas de seu sistema educacional, a exemplo dos países da União Europeia, cuja política de reforma culminou, no ensino superior, com o acordo de Bolonha.

No Brasil, em dezembro de 1996, foi promulgada a atual Lei de Diretrizes e Bases da Educação Nacional, cujo prazo para implantação das últimas ações nela previstas seria 2016, ou seja, vinte anos depois. Para adentrar um pouco neste cenário, destacam-se, aqui, alguns pressupostos concebidos para o Ensino Médio, tendo em vista que cabe a esta 
etapa do sistema educacional um grande desafio, qual seja o de receber os alunos oriundos do ensino fundamental e corrigir os desvios de formação apresentados por eles e preparálos para o ensino superior, para o mercado de trabalho e para a sociedade em geral.

\section{A PERSPECTIVA HUMANISTA E TECNOLÓGICA NO SISTEMA EDUCACIONAL BRASILEIRO: TENTATIVA DE REVERTER A DEFASAGEM}

Internacionalmente, a preocupação com a educação é, em essência, a de direcionar o indivíduo para estratégias cognitivas que lhe permita construir respostas para os problemas, fundamentado na pedagogia do "aprender a aprender". Portanto, é mais importante que o sujeito desenvolva trajetórias cognitivas de aquisição, elaboração, descoberta, construção de conhecimentos. Segundo a Unesco (2004), dois princípios caracterizam a maioria das tentativas de definição do que é uma educação de qualidade: primeiro, o desenvolvimento cognitivo do educando como o objetivo mais importante de todo o sistema educativo; e o segundo é o papel que desempenha a educação na promoção de atitudes e de valores relacionados com a conduta cívica. Tudo isso subsidiado pela criação de condições propícias para o desenvolvimento afetivo e criativo do educando.

No Brasil, o sistema educacional público vem passando por reformulações em busca do resgate da qualidade, norteado pelas premissas da Lei de Diretrizes e Bases da Educação Nacional (LDB), Lei n. ${ }^{\circ}$ 9.394/96, que busca conciliar humanismo e tecnologia, ou seja, conhecimento dos princípios científicos que presidem a produção moderna, exercício da cidadania plena, formação ética e autonomia intelectual.

O Ensino Fundamental, da rede pública e privada, é avaliado pelo Sistema Nacional de Avaliação da Educação Básica, de responsabilidade do Instituto Nacional de Estudos e Pesquisas Educacionais (INEP), e os alunos matriculados no quinto e nono ano (quarta e oitava série), são submetidos à prova de Avaliação Nacional do Rendimento Escolar (Anresc), conhecida como Prova Brasil, e pela Avaliação Nacional da Educação Básica (Aneb), que mede o desempenho dos estudantes e levanta informações sobre escolas, professores e diretores, conforme Varela (2007). 
A prova de língua portuguesa, de alunos da $8^{\mathrm{a}}$ série do Ensino Fundamental, elaborada pela Fundação Carlos Chagas, que costumeiramente tem como objetivo avaliar gênero, estrutura e temática de textos, selecionados para esse nível de escolaridade. Os alunos acertam em média $46 \%$ das questões desta prova. Os resultados permitiram afirmar que as dificuldades apresentadas pelos alunos nessa prova decorrem, em sua maioria, de leitura fragmentada, restrita à decodificação de sinais gráficos. Para a $8^{\mathrm{a}}$ série, esperava-se uma compreensão mais global, interpretativa e contextualizada dos textos, comprovando que os alunos chegam ao Ensino Médio com deficiências de leitura.

Especificamente, a reorganização curricular do Ensino Médio brasileiro está baseada na definição de três grandes áreas: a área de Linguagens, Códigos e suas Tecnologias, a de Ciências da Natureza, Matemática e suas Tecnologias e a de Ciências Humanas e suas Tecnologias. Cada área é composta por um conjunto de competências e habilidades a serem construídas pelos educandos, ao longo de três anos de Ensino Médio.

A educação média está concebida sobre alguns eixos básicos, tais como: a) flexibilidade para atender a diferentes pessoas e situações diante das mudanças permanentes, que caracterizam o mundo da sociedade da informação; b) diversidade que garanta a atenção às necessidades de diferentes grupos em diferentes espaços e situações; c) contextualização que, assegurando uma base comum, diversifique os trajetos, permitindo a constituição de significados e sentidos à aprendizagem e ao aprendido.

O alcance dos objetivos pedagógicos delineados pela proposta de reformulação do Ensino Médio brasileiro somente se concretizará, caso se coloque em ação estratégias interacionistas, que promovam o intercâmbio cognitivo, a troca social e a organização das informações, em paralelo com a satisfação emocional dos participantes, pautada numa expressão personalizada e criativa. Contudo, observa-se que as consequências de uma escolarização precária retardam a aprendizagem e o desenvolvimento cognitivo do aluno, acarretando problemas cumulativos que trarão reais prejuízos para sua vida, conforme apontam os indicadores divulgados pelas instituições responsáveis pela avaliação da qualidade da educação brasileira.

Ampliando este cenário, com a pretensão de melhor subsidiar a formação de opinião sobre a preparação do sujeito social, para usar criteriosamente e 
significativamente as massmedia, apresentam-se a seguir resultados de pesquisas realizadas no âmbito da universidade, sendo que alguns também não descortinam uma realidade promissora.

\section{RESULTADOS DE EXPERIÊNCIAS}

As pesquisas foram realizadas, de 2010 a 2015, pelos membros do grupo de Pesquisa Ciência da Informação: Cognição, Mediação e Construção do Conhecimento (COGNICIC), integrante do Programa de Pós-Graduação em Ciência da Informação da Universidade Federal da Bahia (UFBA), e registrado no cadastro do CNPq, do qual participam professores e alunos da referida instituição:

a) Competências para acesso e uso da informação em sistemas de EAD: análise do curso interagindo e construindo na rede (2010) é o título da dissertação de Rosana Lima Zaidan, que enfocou a capacitação de profissionais da educação, visando avaliar o desenvolvimento de competências para lidar com as Tecnologias da Informação e Comunicação (TIC). O contexto revelava as dificuldades enfrentadas pelos docentes, no manejo das tecnologias. Observou-se que, apesar do esforço empreendido pelo sistema educacional do Estado da Bahia, durante alguns anos, para capacitar os professores, não foram percebidas mudanças significativas no ambiente escolar, principalmente na formação dos estudantes de ensino médio, no que tange à busca e utilização da informação por meio das TIC. O objetivo geral da pesquisa foi de analisar o grau de apreensão e usabilidade das competências digitais e informacionais dos docentes que participaram do curso de formação continuada Interagindo e Construindo na Rede, ministrado pelo Núcleo de Tecnologia Educacional 1 (NTE1), na modalidade a distancia.

Os resultados mostraram que os professores não desenvolveram as competências digitais e informacionais necessárias para utilizar as tecnologias no ambiente escolar, o que prejudica a capacitação dos alunos em competências informacionais e midiáticas. Foram observados, também, problemas gerenciais e a ausência de estrutura da escola e 
dos laboratórios de tecnologias. Constatou-se, ainda, a inexistência de projetos pedagógicos que contemplassem as tecnologias no processo ensino e aprendizagem. Tais resultados apontam a necessidade de políticas públicas que, de fato, eliminem essas dificuldades e promovam o desenvolvimento de competências docentes para o uso das tecnologias.

b) O Acesso às Fontes de Informação Especializadas na Web (2012) é como se intitula a monografia de Bruno Batista dos Anjos, a qual objetivou identificar as fontes de informação acessadas pelos alunos de graduação do quinto semestre, bem como verificar se os alunos demonstravam competências informacionais para buscar e usar as fontes específicas da CI, na rede. Contrastando com a complexidade do ambiente digital os resultados da pesquisa, apresentados a seguir, evidenciam que os usuários não estão preparados para interagir com as ferramentas tecnológicas oferecidas pela rede e muito menos construir conhecimento:

- O perfil da clientela caracterizou-se por estudantes que chegaram ao Curso de Biblioteconomia e de Arquivologia por acaso, por oportunidade, oriundos do Ensino Médio de Escola Pública, com escolaridade dos pais focada no Ensino Médio, estudantes que declararam gostar de ler e não ter dificuldade de leitura, contudo, cruzando com outros dados coletados, eles apresentam baixa frequência de leitura, pouco tempo dedicado a esta atividade, pouca diversidade de gênero e temática de leitura e chegam a registrar que têm dificuldade de organizar dados e informações para construir argumentos. Infere-se que tais dificuldades advêm das deficiências de resumir, sintetizar, identificar, caracterizar e resolver situações problemas.

- Quanto aos resultados sobre o acesso e uso de ferramentas da web, o autor relatou: dos 31 discentes, do $5^{\circ}$ semestre, investigados, $100 \%$ declararam ter habilidades para acessar a internet; $61 \%$ afirmaram que seus conhecimentos e habilidades em relação ao uso da internet eram caracterizados como nível intermediário; 29\% caracterizaram seus conhecimentos e habilidades no nível básico; e 10\%, no nível avançado; quanto à ferramenta da web mais utilizada, apareciam o Youtube, Windows Live, Orkut, Facebook e o Blog. Dos 31 entrevistados, 14 declararam ter blog; quanto à finalidade de uso das ferramentas da web, 36,5\% declararam usálas para elaboração de trabalhos acadêmicos, $34,9 \%$ para entretenimento e $28,6 \%$ 
para a realização de atividades profissionais; quanto à frequência de utilização da web 2.0 para a realização de pesquisa, 53,3 \% declararam que utilizam o ambiente web todos os dias, $31,3 \%$ apenas uma vez por semana, e 9,4\% uma vez por mês; quanto ao conhecimento de fontes especializadas somente $50 \%$ responderam que conhecem as fontes especializadas, os demais não responderam ou não conheciam; quanto à participação no treinamento da Biblioteca Universitária Reitor Macedo Costa: 61,3\% não participaram; quanto à utilização de banco de dados: $30 \%$ utilizam o Portal Capes, $15 \%$ têm conhecimento da ferramenta repositório, mas desconhecem seu significado, na medida em que a acham desnecessária; quanto ao conhecimento da base de dados LISA: 58,1\% afirmaram ter conhecimento e fazer uso dela para realização de pesquisa, os demais não utilizavam; quanto à indicação de outras bases de dados: $64 \%$ citaram a ERIC, a Emerald, Web of Science e a Scielo.

Infere-se que os resultados apresentados não têm consistência para afirmar o real domínio tecnológico dos alunos no que tange à exploração da potencialidade das ferramentas de descobrimento das fontes de informação de pesquisa citadas por eles, diante da complexidade do processo de busca e na linguagem técnica e domínio de idiomas.

A seguir, relata-se uma experiência exitosa, que pode ser transferida para outras situações que objetivem ampliação de potencial de competências para a leitura crítica de massmedia.

c) Experiência didática nas disciplinas 'fontes especializadas e serviços de informação' (2015) foi concebida e executada pelas professoras Maria Giovanna Guedes Farias e Gabriela Belmont de Farias, com alunos das disciplinas do curso de Biblioteconomia, da Universidade Federal do Ceará (UFC), com o objetivo de analisar a utilização dos mapas conceituais como ferramentas didático-pedagógicas, visando à representação gráfica do conhecimento e auxílio no processo de ensino-aprendizagem.

Os mapas conceituais ganham a forma traçada pelos relacionamentos entre conceitos. Softwares aplicativos para a construção de mapas conceituais, a exemplo do CMapTool e do Inspiration, permitem associar vários recursos aos nós de um mapa. Por exemplo, pode-se associar uma coleção de documentos (texto, páginas web etc.) aos 
mapas, sendo que cada nó, representando um conceito, pode ser relacionado com um ou mais documentos da coleção. É importante observar que a associação é livre e é concebida pelo usuário que manipula as ferramentas de software. (VARELA; BARBOSA; FARIAS, 2014).

Conforme essas autoras, no campo da organização da informação, uma das aplicações possíveis da técnica do mapa conceitual é no processo de indexação de conteúdo, o que pode ser otimizado com a aplicação de softwares especializados, que agilizam a associação de conceitos, facilitando a fase de busca e recuperação da informação. Nessa aplicação, a função do mapa conceitual é de ser um eficiente indexador de conteúdo. Faria (1995) ratifica a contribuição significativa da técnica dos mapas conceituais, suportada por softwares, abordando uma aplicação no contexto de Ambientes Virtuais de Aprendizagem (AVA). Isto porque, em uma comunidade virtual suportada por esses ambientes, os grupos possuem sua própria coleção de documentos. No entanto, o ideal é possibilitar a socialização da coleção entre todos os participantes, fazendo com que a busca seja possível na coleção total de documentos, isto é, no acervo integral de toda a comunidade virtual de aprendizagem, não se limitando, portanto, à coleção particular de um dos grupos do ambiente.

Participaram da pesquisa 38 discentes do curso de Biblioteconomia da UFC, sendo 22 da disciplina Fontes Especializadas (ministrada no quarto semestre) e 16 da disciplina Serviços de Informação (ministrada no sétimo semestre).

Durante a análise de dados realizada por Farias e Farias (2015), destaca-se a categoria desafios na construção dos mapas conceituais, a qual visou observar as dificuldades encontradas pelos alunos no momento da construção dos mapas conceituais, as quais eles identificaram como sendo: definir a questão local; ligar corretamente os conceitos; encontrar termos; falta de prática; identificar os conceitos principais e saber interligá-los; sintetizar as informações e ideias para inserir no mapa, de forma que contemplasse todo o conteúdo do texto; organizar as informações e ideias de diferentes textos; definir os tópicos partindo do mais geral para o mais específico; e organização estética e de espaço. 
Já a categoria mapas conceituais como facilitadores da construção do conhecimento teve como objetivo identificar se houve compreensão do conteúdo trabalhado em sala de aula, bem como se os mapas se caracterizam como potenciais instrumentos de aprendizagem. Nessa categoria surgiram os seguintes resultados: $92,1 \%$ dos alunos afirmaram ter compreendido o conteúdo trabalhado em sala de aula, enquanto $7,9 \%$ tiveram algum tipo de dificuldade no entendimento do texto por meio da elaboração do mapa.

Ao refletir sobre dificuldades encontradas pelos alunos no momento da construção dos mapas e também sobre a dificuldade no entendimento do texto por meio da elaboração do mapa, Farias e Farias (2015) consideram que os alunos precisam desenvolver determinadas competências, se alfabetizando para a utilização desta ferramenta de aprendizagem, tendo como orientação as ponderações de Torres (2007): saber como aprender, como selecionar o que conhecer, como compreender fatos e fenômenos, como estabelecer suas relações interpessoais, como analisar, refletir e agir sobre esta nova ordem das coisas.

\section{CONSIDERAÇÕES FINAIS}

As inovações no âmbito das TIC têm alcançado seus propósitos de criação de ferramentas cada vez mais velozes, econômicas, interativas e hipertextuais, que aproximam o indivíduo da rede e seus aplicativos, no entanto, numa sociedade desigual, como no Brasil, o problema não é apenas tecnológico, mas educacional e político, considerando que grande parte da população, como registrado nos estudos estatísticos, não usufrui das ações de inclusão digital, tanto por falta de ferramentas tecnológicas como por carência de pré-requisitos cognitivos para a leitura das complexas linguagens tecnológicas e interpretação e compreensão de conteúdos, conforme foi evidenciado ao longo deste estudo.

Não se pode negar o significado da internet, e das muitas soluções digitais que ela introduziu, na intensificação da distribuição do conhecimento e do acesso à informação e na ampliação das possibilidades de educação do sujeito social. No entanto, 
a complexidade e a multidimensionalidade da oferta de serviços na rede é uma barreira para aquele que não é proficiente em leitura, ou seja, aquele que não tem discernimento para selecionar, escolher, interpretar e usar significativamente a informação.

A ALFIN/EEES, ou seja, o Projeto de Alfabetização Informacional do Espaço Europeu de Ensino Superior (2005) traçou as competências genéricas relacionadas com a alfabetização informacional e como uma condição para a formação plena do sujeito social incluiu a competência tecnológica, que se ocupa da teoria e da prática do formato, desenvolvimento, seleção e utilização, avaliação e gestão dos recursos tecnológicos, atendendo aos seguintes aspectos: conhecimentos científicos teóricos das TIC e meios de comunicação; habilidades de manejo; alfabetização audiovisual; alfabetização informática e telemática; valorização do impacto das TIC e dos meios de comunicação de massa na sociedade e na educação; conhecimento dos materiais disponíveis no mercado: meios de comunicação de massa, vídeos, software, espaços web e avaliação da qualidade técnica, pedagógica e funcional; conhecimento das possíveis aplicações em educação; planejamento, gestão e avaliação de atividades educativas com apoio tecnológico; delineamento de desenvolvimento de materiais educativos em suporte tecnológico; e organização dos recursos pedagógicos centrais (ALFIN/EEES, 2005).

No Brasil, o perfil do usuário da rede - o que ele pesquisa, como pesquisa e para que pesquisa - destaca a forte relação sobre a educação e renda no acesso e uso da internet. E no que tange aos indicadores de ensino, sobretudo focando os índices de alfabetismo versus analfabetismo, há que se dar atenção ao envolvimento do aspecto cognitivo na consecução de operações complexas e superiores para a codificação e decodificação dos conteúdos, que estão implícitas na cadeia de ações para a obtenção do conhecimento.

A este respeito, há algumas tênues iniciativas no ensino público, que contemplam as tecnologias da informação e da comunicação e os e-learning centrados na alfabetização informacional e digital. Esta iniciativa capacita a quem aprende a enfrentar criticamente os conteúdos e fazer-se autossuficiente, assumindo maior controle sobre seu próprio processo de aprendizagem. Este processo visa desenvolver nos sujeitos uma ampla autonomia de pensamento que lhes permita adquirir, compartilhar e transferir conhecimento. 
As novas linguagens, fruto da assimilação do som e da imagem à fala e à escrita, exigem um sujeito com habilidades específicas de leitura das mensagens veiculadas. Daí a preocupação com o ato de leitura. Esta deve ser compreendida, como o conhecimento do significado pela interpretação do significante. Os signos icônicos, por exemplo, requerem interpretação e, portanto, devem ser lidos e não somente vistos.

Ver uma fotografia ou ver televisão não é a mesma coisa que ler uma fotografia ou ler a televisão, nesse caso, ler significa tomar consciência da representação da imagem, de como foi feita, do seu significado, por fim penetrar na mensagem ideológica ali trazida e, após tal reflexão, aceitá-la ou não, criticando-a quando necessário e incorporá-la, se julgar coerente com seus propósitos de cidadão.

Assim, o valor dos meios de comunicação de massa irá depender do sentido que se lhes dará a partir de uma nova leitura, que poderá ser boa ou não. Contudo, reitera-se que é este grau de qualidade que se espera da educação pública brasileira, de norte a sul do país, o que, evidentemente, depende de vontade e deliberação de ordem política, econômica e social.

\section{Humanism and technology in perspective of information literacy and massmedia}

Abstract: The article analyzes the technological advances in the framework of information and communication in contemporary society, with emphasis on the new technological resources of massmedia and its appropriation by the social subject, highlighting the Brazilian context. On the above, the objective of this work, is to reflect about the contradictions between the complex organization of knowledge, considering the various formats and structures provided by the massmedia, and the lack of proficiency of the individual to understand, adapt and transform knowledge. It presents some results of studies conducted on the subject in question, by members of the research group Information Science: Cognition, Mediation and Construction of Knowledge (COGNICIC), from 2010 to 2015 . The research results showed that teachers and students didn't reach a satisfactory level of mastery of skills, digital competences and informational necessary for their use, management and reflective use at school and in society; and also that management problems and lack of school structure and multimedia laboratories have hindered the process of incorporating technology in the classroom and training teachers as multipliers. These results reiterate the argument defended by the 
COGNICIC that the development of skills and reading skills is a prerequisite for access and participation in collaborative networks of knowledge construction. In theory, overcoming the lag framework will occur if they are designed and implemented educational projects that enhance the formation of critical subjects, creative and protagonists of their autonomy.

Keywords: Information literacy. Technological competence. Massmedia. Readingproficiency. Humanism.

\section{REFERÊNCIAS}

AÇÃO EDUCATIVA \& INSTITUTO PAULO MONTENEGRO. Indicador de Alfabetismo Funcional- INAF, Estudo especial sobre alfabetismo e mundo do trabalho. $2016 . \quad$ Disponível em: $<\underline{\text { http:} / / w w w . i p m . o r g . b r / p t-~}$ br/programas/inaf/relatoriosinafbrasil/Paginas/Inaf-2015---Alfabetismo-no-Mundo-doTrabalho.aspx>. Acesso em: 16 out. 2016.

ALFIN/EEES. Habilidades e competencias de gestión da información para aprender a aprender en el marco del espacio europeo de enseñanza superior. Espanha : Universidade de Granada, 2005. Disponível em: www.um.es/dp-lenguaespa/.../habilidades-competencias.pdf. Acesso em: 15 out. 2016.

ALLIENDE, Felipe. Leitura: teoria, avaliação e desenvolvimento. Porto Alegre. Artes Médicas, 1987.

ANJOS, B. B. O Acesso às fontes de informação especializadas na web. Salvador, 2012. 50f. Monografia(Graduação em biblioteconomia) - Universidade Federal da Bahia, 2012.

BRASIL. Lei de Diretrizes e Bases da Educação Nacional. Lei n ${ }^{\circ}$ 9394, 20 de dezembro de 1996.1 Disponível em: $<$ https://www.planalto.gov.br/ccivil_03/Leis/L9394.htm>. Acesso em: 20 de outubro de 2016.

FARIAS, M. G. G.; FARIAS, G. B. Aplicação de mapas conceituais como ferramentas didático-pedagógicas na área de recursos e serviços de informação. Biblios (Lima), v. 1, p. 13-27, 2016.

INSTITUTO BRASILEIRO DE GEOGRAFIA E ESTATÍSTICA (IBGE). Censo 2010. <Disponível em http://censo2010.ibge.gov.br/>. Acesso em 20 out. 2016.

INSTITUTO BRASILEIRO DE GEOGRAFIA E ESTATÍSTICA (IBGE). Pesquisa Nacional por Amostra de Domicílios - PNAD. Disponível em: 
<http://www.ibge.gov.br/home/estatistica/pesquisas/pesquisa_resultados.php?id_pesqui $\underline{\mathrm{sa}=40}>$. Acesso em: 20 out. 2016.

INSTITUTO PAULO MONTENEGRO. Indicador de Alfabetismo Funcional - INAF, Estudo especial sobre alfabetismo e mundo do trabalho. 2016. Disponível em: $<$ http://www.ipm.org.br/pt-br/programas/inaf/relatoriosinafbrasil/Paginas/Inaf-2015--Alfabetismo-no-Mundo-do-Trabalho.aspx >. Acesso em: 16 out. 2016.

INSTITUTO PRÓ-LIVRO. Retratos da Leitura no Brasil. 2015. Disponível em: $<$ http://prolivro.org.br/home/atuacao/25-projetos/pesquisas/3900-pesquisa-retratos-daleitura-no-brasil-48>. Acesso em: 19 out. 2016.

KLEIMAN, Ângela. Texto \& leitor: aspectos cognitivos da leitura. 6. ed., Campinas: Pontes, 1999.

QUIN, Robyn. Aprender a mirar: el lugar de los textos visuales nel currículo escolar. Comunicar, v. 12, 1999. p. 131-139. Disponível em: <http://engels.fe.unb.br/vucourses/MCAEAD>. Acesso em 16 out. 2016.

SILVA, Maria Helena B. R. A produção de material para o ensino à distância. In: BALLALAI, Roberto (org.). Educação a distância. Niterói/Rio de Janeiro: Fundação Brasileira de Educação/Centro Educacional de Niterói/GRAFC N, 1991.

STEMLER, Luann K. Educational Characteristics of Multimedia: a literature review. Jl. Of Educational Multimedia and hypermedia, v. 6, n. 3/4, p. 339-359, 1997.

TORRES, Márcia Zampieri. Situações-problema como recurso de avaliação de competências no Enem. In: Ministério da Educação. (Org.). Eixos cognitivos do Enem, Brasília, 2007, p. 31-53.

VARELA, A. V.; BARBOSA, M.; FARIAS, M. G. G. Mediação em múltiplas abordagens. Inf. Inf., Londrina, v. 19, n. 2, p. 138 -170, maio./ago. 2014.

VARELA, A. V. Informação e Autonomia: a mediação segundo Feuerstein. 1. ed. São Paulo: Editora SENAC, 2007, v. 1. 368p.

UNESCO. Educação para todos. El imperativo de la calidad. Paris, 2004.

ZAIDAN, R. L. Competências para acesso e uso da informação em sistemas de

EAD:análise do curso interagindo e construindo na rede. Salvador, 2010, 169f. (Dissertação). - Universidade Federal da Bahia, Programa de Pós-Graduação em Ciência da Informação, 2010. 
Informações das Autoras

\section{Aida Varela Varela}

Professora do Instituto de Ciência da Informação e do Programa de Pós-Graduação em Ciência da Informação da Universidade Federal da Bahia.

Email|:varela@ufba.br

\section{Marilene Lobo Abreu Barbosa}

Professora aposentada do Instituto de Ciência da Informação da Universidade Federal da Bahia.

Email: marilene@ufba.br

\section{Maria Giovanna Guedes Farias}

Professora do Departamento de Ciências da Informação e do Programa de Pós-Graduação em Ciência da Informação da Universidade Federal do Ceará.

Email: giovannaguedes@ufc.br

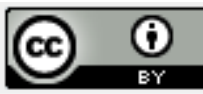

